\title{
POTENTIALS OF Crateva adansonii AS CORROSION INHIBITOR ON LOW CARBON STEEL IN ACIDIC MEDIUM
}

\author{
A.B. Anwo ${ }^{1}$, A.A. Akinsiku ${ }^{1}$, O. Aladesuyi ${ }^{1}$, C.O. Ajanaku ${ }^{1}$, O.S.I. Fayomi ${ }^{2}$ \\ and K.O. Ajanaku, ${ }^{1, *}$ \\ ${ }^{1}$ Department of Chemistry, Covenant University, P.M.B. 1023, Ota, Ogun State, Nigeria \\ ${ }^{2}$ Mechanical Engineering Department, Covenant University, Ota, Ogun State, Nigeria \\ *E-mail: kola.ajanaku@covenantuniversity.edu.ng
}

\begin{abstract}
The potentials of Crateva adansonii extract from the plant leaf as corrosion inhibitive action on the substrate in acidic was embarked upon in this research using weight loss and linear polarisation techniques spanning four temperatures $(303-333 \mathrm{~K})$. The low carbon steel coupons were immersed in blank of the acidic media and also observed at various dosage level ranging from $0.08-0.8 \mathrm{~g} / \mathrm{L}$ for the extract. The inhibition efficiency of the extracts and corrosion rate on mild steel was measured at room temperature for $504 \mathrm{~h}$ and $21 \mathrm{~h}$ at the four temperatures. The maximum inhibition efficiency was found to be $84.95 \%$ for Crateva adansonii extract in acidic medium respectively. The weight loss decreased with increase in Crateva adansonii extract due to higher degree of surface coverage. The inhibition potential increased with increase in concentration at $0.8 \mathrm{~g} / \mathrm{L}$ as optimum, but decreased with rise in temperature as a result of the desorption of the extracts from the low carbon steel surface. Polarization technique indicated a reduced corrosion rate in all test solutions. The use of Crateva adansonii extract has been found to inhibit corrosion of low carbon steel in this study and hence their usage is hereby proposed in acidic medium.
\end{abstract}

Keywords: Weight loss, Adsorption isotherm, Coupons, Crateva adansonii

(c) RASĀYAN. All rights reserved

\section{INTRODUCTION}

Metal degradation and corrosion are issues that cannot be disregarded when considering the utilisation of metal in our society. This destructive effect has been seen when the metal in the combined state tends to revert to its most stable natural state on exposure to certain environmental conditions. This effect of corrosion transition has drastically and technically affected several industries resulting in losses and damages with a large deficit. ${ }^{1,10,11}$ Corrosion inhibitors are chemical substances that retards corrosion process of a given metal exposed to a specific environment leading to the reduction of the overall corrosion rate at that site. ${ }^{16}$ Added in low sufficient concentration in a media (acidic, saline and the likes), cooling waters, steam, and many other environment. Now scientists are beginning to search for ecofriendly inhibitors such as green inhibitors. Crateva adansonii is popularly refers to as Sacred Garlic Pea in the family Capparaceae. ${ }^{2}$ It can be called ungududu (Hausa, Northern Nigeria), eegun orun or ajanaka (Yoruba, western Nigeria), amakarode (Igbo, eastern Nigeria) and "sacred barna" in India. It is reported to have serve as pain reliever for easing headaches and used for treatment of jaundice and yellow fever. ${ }^{2,23,24,25,28}$ The flavonoids, saponins, alkaloids, trepenoids and cardic glycoside are phytochemical indicators deduced from the Crateva adansonii plant extract. ${ }^{2,3}$ The aim of this research work is to study the potentials of Crateva adansonii as corrosion inhibitor on low carbon steel in acidic media.

\section{EXPERIMENTAL}

\section{Materials and Method}

\section{Preparation of Crateva adansonii Leaf Extract}

The leaf of Crateva adansonii plant are washed, air dried for a period of 14 days and ground into powder weighing about $2.5 \mathrm{~kg}$ in all. The extract of the dried powder leaf were removed by soaking in ethanol for $72 \mathrm{~h}$ and filtering afterward. ${ }^{6}$ Solvent removal by use of rotary evaporator at $60-65{ }^{\circ} \mathrm{C}$ temperature thereby concentrated to about $10 \%$ residue of the extract and left at room temperature to evaporate in open air. From this $0.08,0.2,0.4,0.6,0.8 \mathrm{~g} / \mathrm{L}$ dosage level of the proposed ecofriendly extract were

Rasayan J. Chem., 13(2), 1283-1292(2020)

http://dx.doi.org/10.31788/RJC.2020.1325455 
prepared as corrosion inhibitor, by injecting $(0.08-0.8 \mathrm{~g} / \mathrm{L})$ extract in $1.75 \mathrm{M} \mathrm{HCl}$ respectively and the same concentrations into $150 \mathrm{ml}$ of $1.75 \mathrm{M} \mathrm{HCl}$ for linear polarisation resistance analysis at a scan rate of $0.5 \mathrm{mV} / \mathrm{s}$. Moreso, the acidic medium used was hydrochloric acid $(\mathrm{HCl})$, with fuming ability of $37 \%$ and a molecular weight of $36.45 \mathrm{~g} / \mathrm{mol}$ obtained from R \& M chemicals. About $1.75 \mathrm{M} \mathrm{HCl}$ was diluted with the aid of double-distilled water. The concentration was varied in an acidic medium of 200 $\mathrm{ml} \mathrm{HCl}$ of each experiment respectively.

\section{Weight Loss Method (Metal Composition)}

The low carbon steel used for this study has a chemical composition as shown in Table -1 .

Table -1: Chemical Composition of Low Carbon Steel

\begin{tabular}{|c|c|c|c|c|c|c|c|c|c|}
\hline Element & $\mathrm{Fe}$ & $\mathrm{C}$ & $\mathrm{Si}$ & $\mathrm{Mn}$ & $\mathrm{Al}$ & $\mathrm{Cr}$ & $\mathrm{P}$ & $\mathrm{S}$ & $\mathrm{Ni}$ \\
\hline \%Composition & 99.2 & 0.15 & 0.17 & 0.43 & 0.006 & 0.001 & 0.02 & 0.033 & 0.007 \\
\hline
\end{tabular}

Corrosion rate and the Inhibition efficiency was calculated from weight loss using the above expression in equation 1 and 2, $C_{R}$ is the corrosion rate of the low carbon steel in Mill per year (Mpy); 143,700 is the constant that was used in the calculation of corrosion rate, $W l$ change in weight loss of the substrates after immersion, The density of the low carbon steel is denoted with the value of $7.85, \mathrm{~A}$ is the area of the coupon in $\mathrm{cm}^{2}$ and $\mathrm{t}$ is the exposure time (h). $\Delta \mathrm{W}_{0}$ is the change in weight in uninhibited solution and $\Delta \mathrm{W}_{\text {inh }}$ is the change in weight with inhibited solution for inhibition efficiency of the eco- friendly solution on the substrates. ${ }^{7,10,29}$

\section{Electrochemical Measurement (Linear Polarization Resistance, LPR)}

The linear polarisation resistance was measured using Autolab Nova 2.1.1 potentiostat galvanostat. The polarisation curves were recorded from $100 \mathrm{~mA}$ to $100 \mathrm{nmA}$ concerning corrosion current at a scan rate of $0.5 \mathrm{mV} / \mathrm{s}$. The tafel parameters obtained and listed in the Table- 3 to 6 . The corrosion inhibition efficiency $\eta p(\%)$ was calculated from the measured corrosion current density $\left(I_{c o r r}\right)$ by the following relationship.,

$$
\eta p(\%)=\frac{I_{\text {ocorr }}-I_{\text {icorr }}}{I_{\text {ocorr }}} \times 100
$$

Where, $I_{\text {ocorr }}$ and $I_{\text {icorr }}$ are the corrosion current densities of the substrate in the absence and presence Crateva adansonii leaf extract of $0.5 \mathrm{mV} / \mathrm{s}$ scanning rate.

\section{RESULTS AND DISCUSSION}

\section{Phytochemical Screening of Crateva adansonii (CA) leaf Extract}

Table-2, the CA ethanolic leaf extract showed the presence of phyto-constituents in alkaloid, terpenoid, Flavonoids, cardiac glycoside, phenol, saponins and absences of tannins. ${ }^{2,3}$

Table -2: Intensities of Secondary Metabolites in Crateva adansonii leaf.

\begin{tabular}{c|c}
\hline Constituent & Intensity of CA Leaf Extract \\
\hline Phenols & ++ \\
\hline Flavonoids & +++ \\
\hline Tannins & - \\
\hline Alkaloid & +++ \\
\hline Cardiac glycosides & ++ \\
\hline Saponins & ++ \\
\hline Terpenoids & ++ \\
\hline
\end{tabular}

Keys: (+++) Intense, (++) Moderate, (+) Mild, (-) Absent. 
Gravimetric Studies (Weight Loss) with Exposure Period for Crateva adansonii Extract (CA) at Room Temperature of (504 h) at Elevated Temperature (21 h)

The effect of Crateva adansonii extract concentrations on weight loss of low carbon steel at room temperature (504h) and elevated temperature (21h) using gravimetric method as shown in Fig.-2(a) and 2(b to e). It is observed that there is a weight loss decrease with increasing concentrations of the inhibitor during their exposure period in all tested solutions. For uninhibited solution, the progression of the plot was found to be uniform. This Infers that the weight loss of the system at the same inhibitive concentrations are concentration and temperature dependent. This is in agreement in what was observed by. ${ }^{9,13,15}$ in their study on the use of ecofriendly inhibitors from plant extract.

The effect of $(\mathrm{CA})$ extract concentrations on low carbon steel using gravimetric studies at a temperature of (303-333 K) is as shown in Fig.-2(b to e). At $303 \mathrm{~K}$, results showed that the concentration with 0.08 $\mathrm{g} / \mathrm{L}$ inhibitive extract at $3-9 \mathrm{~h}$ exposure time give rise to a negligible decrease in weight loss. Afterwards, upon addition of $0.2-0.8 \mathrm{~g} / \mathrm{L}$ CA leaf extract, a uniform plot was maintained shown in Fig.-2(b); this suggest the inhibitive actions of the extract molecule are been adhere onto the metal surface. At $313 \mathrm{~K}$, with a concentration of $0.08 \mathrm{~g} / \mathrm{L}$, a little reduction in weight loss concerning exposure time was observed. However, with concentrations ranging from $0.2-0.8 \mathrm{~g} / \mathrm{L}$, a negligible reduction in weight loss, which gives rise to the uniform plot, as shown in Figure -2(c). At $323 \mathrm{~K}$, the concentration 0.08 $0.2 \mathrm{~g} / \mathrm{L}$ indicates a slight reduction of weight loss, afterwards at $0.4-0.8 \mathrm{~g} / \mathrm{L}$ a uniform plot is maintained as shown in Fig.-2(d). At $333 \mathrm{~K}$, this elevated temperature result showed a slight reduction in weight loss within the exposure time 3-12h. Thereafter, having a further increase in the weight loss trend from 12-21h; which results in temperature rise of the system as shown in Fig.-2(e).This infers that the weight loss of the system at the same inhibitor are concentration and temperature dependent. ${ }^{15,26,27}$

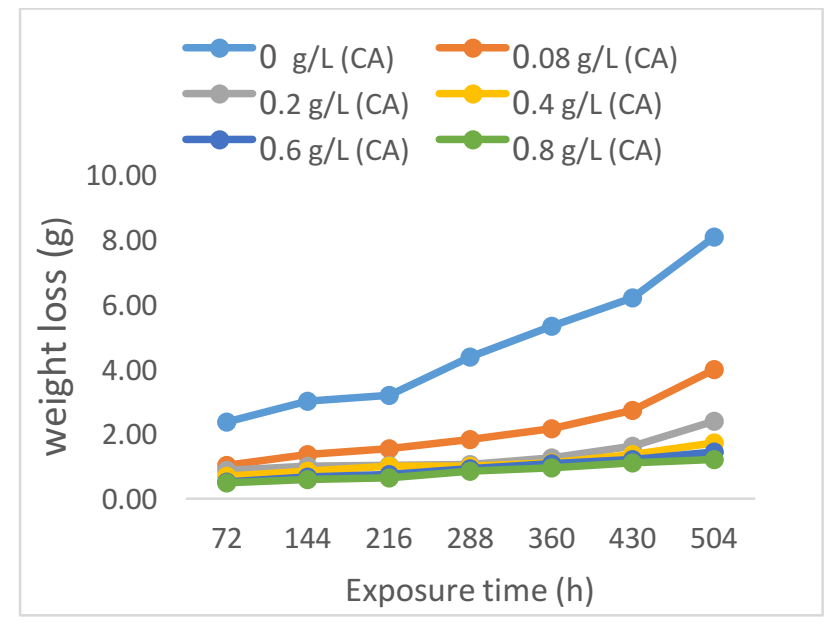

(a)

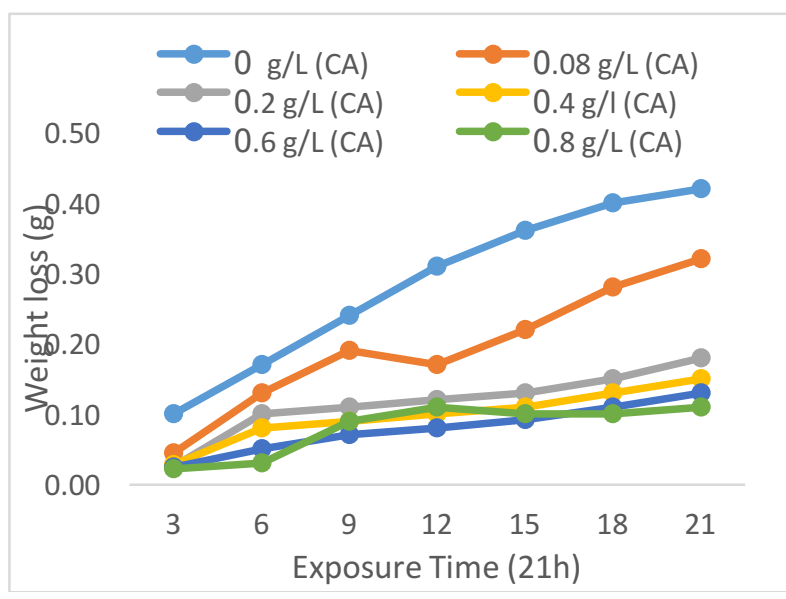

(b)

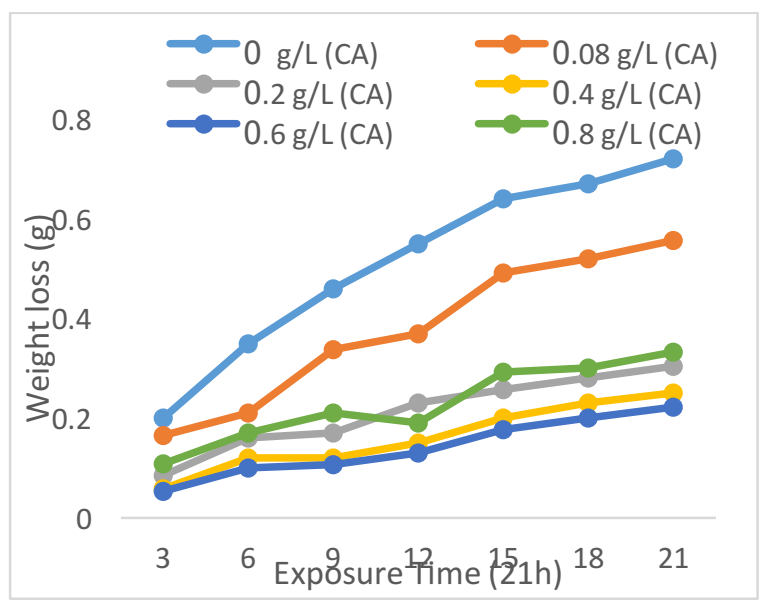

(c) 


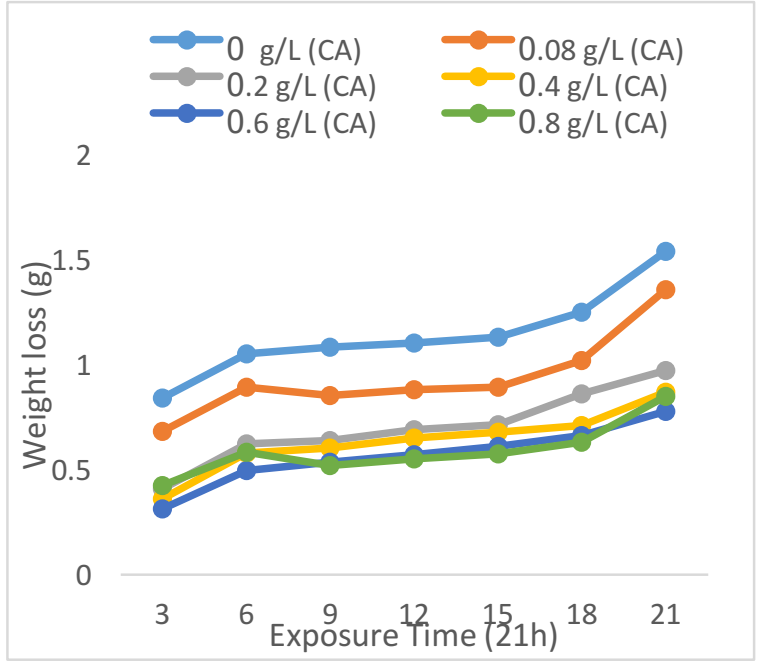

(d)

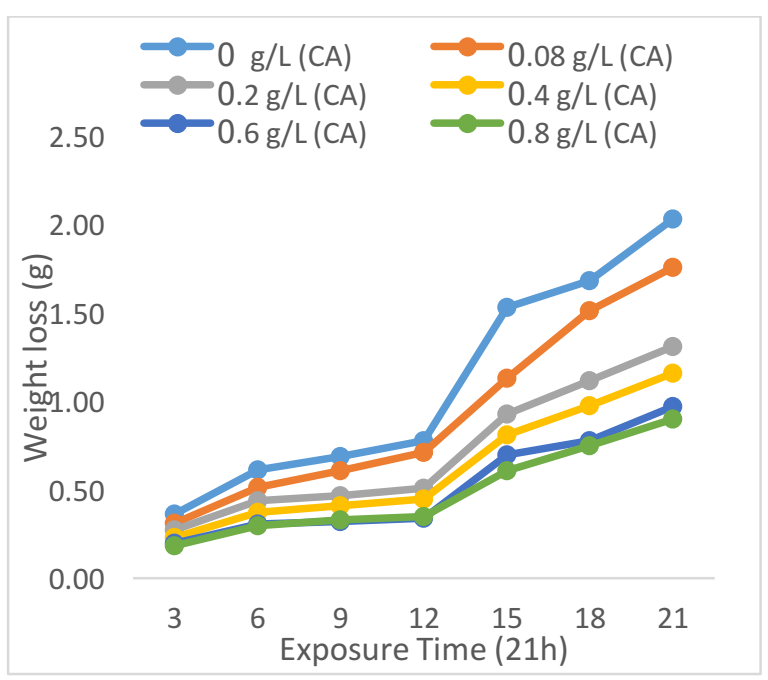

(e)

Fig. -2: The Effect of CA Extract Concentrations on Weight Loss of Low Carbon Steel (a) Room Temperature $298.16 \mathrm{~K}$ (b) $303 \mathrm{~K}$ (c)313 K (d) 323 (e) $333 \mathrm{~K}$

Variation of Inhibition Efficiency with Exposure Period (504h) using Crateva adansonii (CA) at Room Temperature (Gravimetric Method)

The inhibitive effect of Crateva adansonii extract on low carbon steel at room temperature is as shown Fig.-3(a). From all indications, inhibition efficiency of the system increases with increasing CA leaf extract dosage level, probably due to coverage of extract molecules adhering to the substrates as attested by ${ }^{13}$.The inhibitive actions of the extracted molecule on the system result in optimum inhibition efficiency of $84.95 \%$ (CA) concentration of $(0.8 \mathrm{~g} / \mathrm{L})$. However, the inhibitive nature of the extract may be due to presence of hetero atoms present in the phytochemical constituents such as tannin-containing leaf extracts which are reported to exhibit varying inhibition efficiency as shown in the progression of the plot in Fig.-3(a). ${ }^{4,26,28}$

The effect of CA extract concentrations on inhibition efficiency of low carbon steel is as shown in Fig.3 (b to e). At $303 \mathrm{~K}$, The concentration of $0.08 \mathrm{~g} / \mathrm{L}$ CA leaf extract showed inconsistent behavior of the extract molecules inhibitive actions on the substrates with respect to exposure period; which might results to desorption of the extract molecules away from the metal surface as shown in Fig.-3(b). However, at concentrations of $0.2-0.8 \mathrm{~g} / \mathrm{L}$ a steady-state trend were observed having increase in inhibition efficiency with increasing concentrations of extract molecules. The concentration of $0.08 \mathrm{~g} / \mathrm{L}$ of CA leaf extract at $313 \mathrm{~K}$, shows that the inhibition efficiency increases till exposure time of $12 \mathrm{~h}$, afterwards decreases with time, it was also observed that a uniform plot is maintained at concentration range of $0.2-0.8 \mathrm{~g} / \mathrm{L}$ of CA leaf extract respectively as shown in Fig.-3(c). At a temperature of $323 \mathrm{~K}$, a slight increase and decrease in inhibitive potential at $0.08 \mathrm{~g} / \mathrm{L}$ concentration of CA leaf extract, further increase in the concentration of CA leaf extract from $0.2-0.8 \mathrm{~g} / \mathrm{L}$, led to a uniform plot up till $15 \mathrm{~h}$ of exposure time followed by inconsistent increase and decrease at 18 and $21 \mathrm{~h}$ of exposure as shown in Fig.-3(d). At $333 \mathrm{~K}$, a uniform increase in inhibitive trend is observed for all concentrations except 0.08 $\mathrm{g} / \mathrm{L}$ which at $15 \mathrm{~h}$ of exposure time rapidly, at latter end of $18-21 \mathrm{~h}$ a steady state trend inhibitive action is observed as shown in Fig.-3(e). The study of inhibition efficiency is temperature dependent. ${ }^{5,11,25}$

Variation of Corrosion rate with Time at Room Temperature (504h) Using (Gravimetric method) The effect of Crateva adansonii (CA) leaf extract concentrations on corrosion rate of low carbon steel at room temperature is as shown in Fig.-4(a). It was observed that corrosion rate of the system decreases in respect to an increasing concentrations of the extract molecules. Thus, reducing the available sites from the aggressive environment.

The effect of CA extract concentrations on corrosion rate of low carbon steel is as shown in Fig.-4(b to e). At $303 \mathrm{~K}$, Fig.-4(b), the concentration of $0.08 \mathrm{~g} / \mathrm{L}$ of CA leaf extract shows a negligible decrease in corrosion rate for 3-9h. Also, a further decrease in corrosion rate was observed as the concentration of CA leaf extract $(0.2-0.8 \mathrm{~g} / \mathrm{L})$ were added thereby maintaining a uniform plot of a steady state decrease with respect to the exposure time. At $313 \mathrm{~K}$, Fig. -4(c) an inconsistent increase and decrease in corrosion 
rate concerning exposure time were observed. ${ }^{4,} 26$ At $323 \mathrm{~K}$, a uniform plot was observed for all concentration of CA leaf extract, having a rapid decrease in corrosion rate as the concentrations increases with exposure time as shown in Fig.-4(d). At $333 \mathrm{~K}$, it is observed that at all concentration of CA leaf extract, a little decrease in corrosion rate with exposure time from $3-12 \mathrm{~h}$ was observed at all concentration of CA; having maintained a uniform plot of decrease in corrosion rate and increasing with time of 12-21h, as shown in Fig.-4(e). ${ }^{5,17,23}$

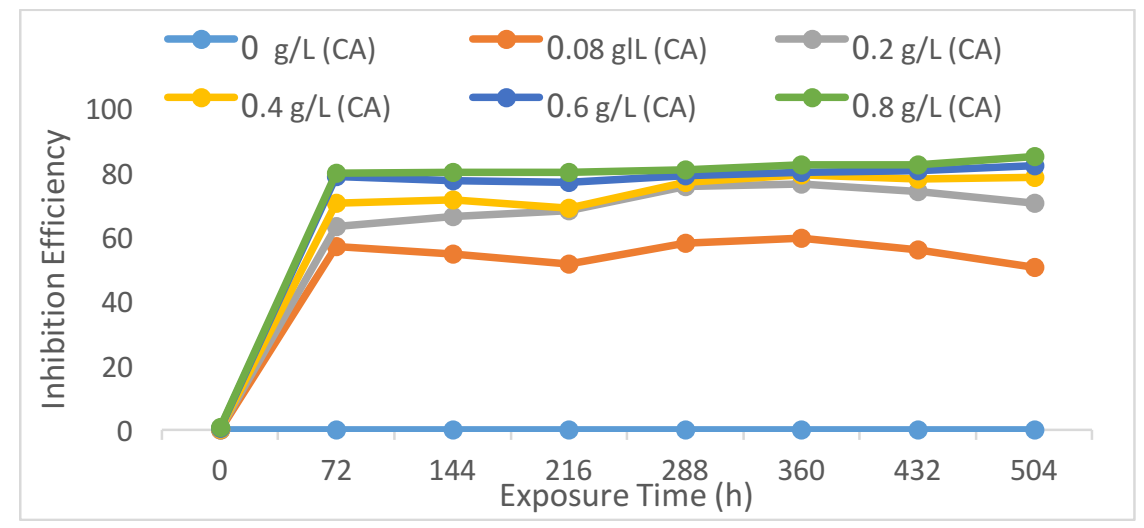

(a)

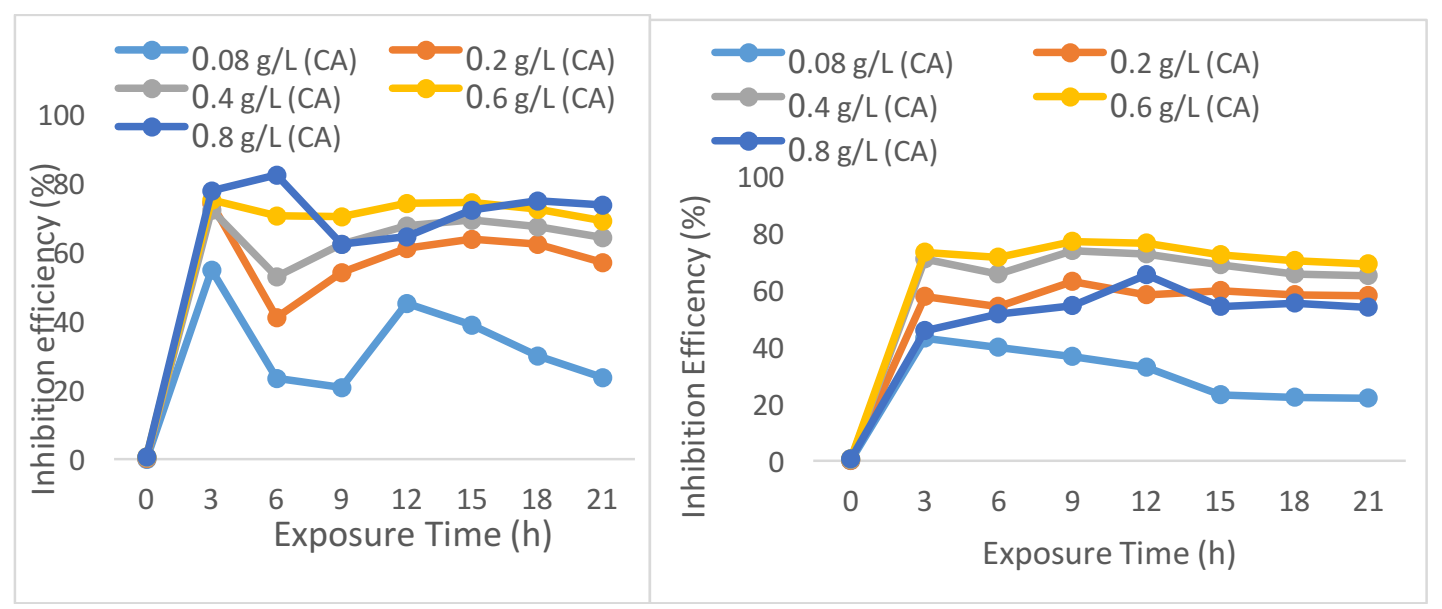

(b)

(c)

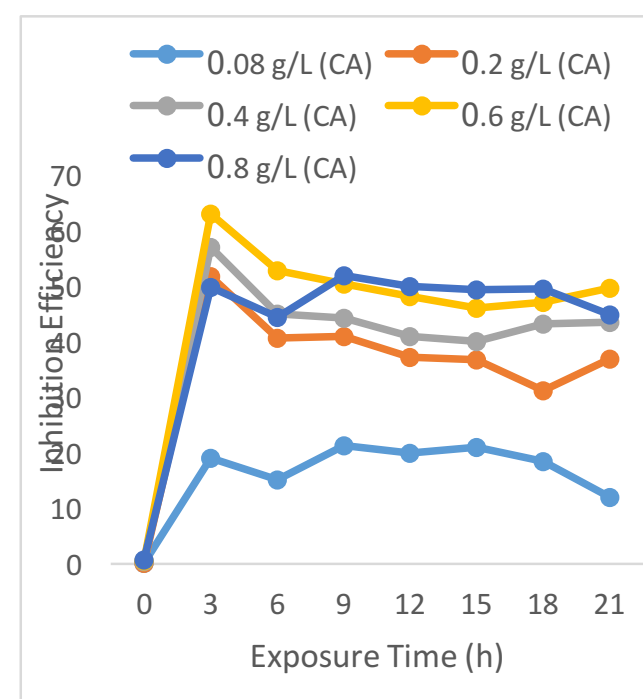

(d)

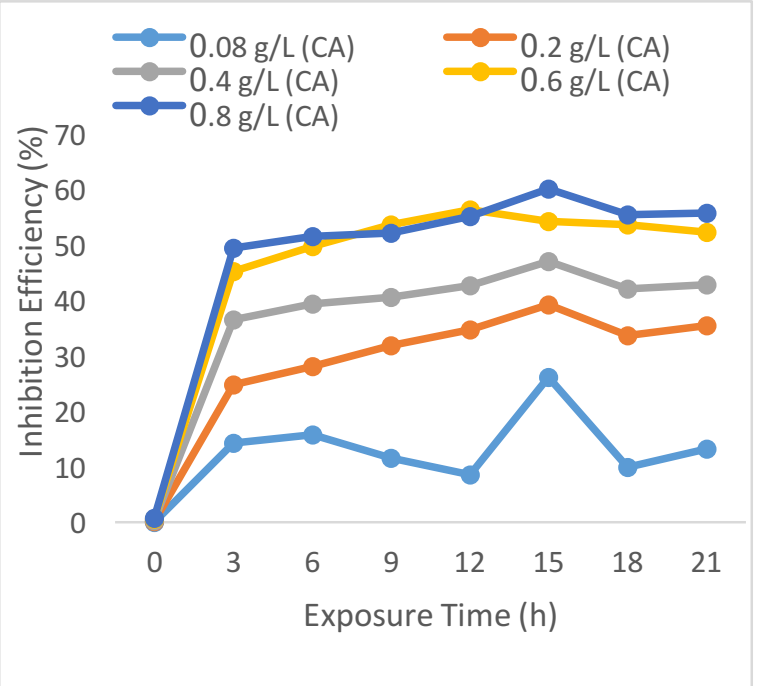

(e)

Fig. -3: The effect of CA extract concentrations on Inhibition efficiency of low carbon steel (a) room temperature $298.16 \mathrm{~K}$ (b) $303 \mathrm{~K}$ (c)313 K (d) 323 (e) $333 \mathrm{~K}$ 


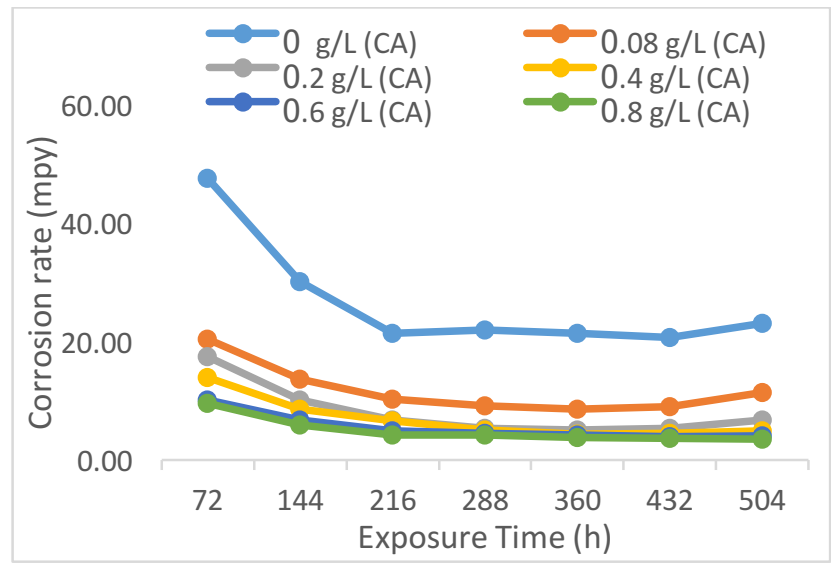

(a)

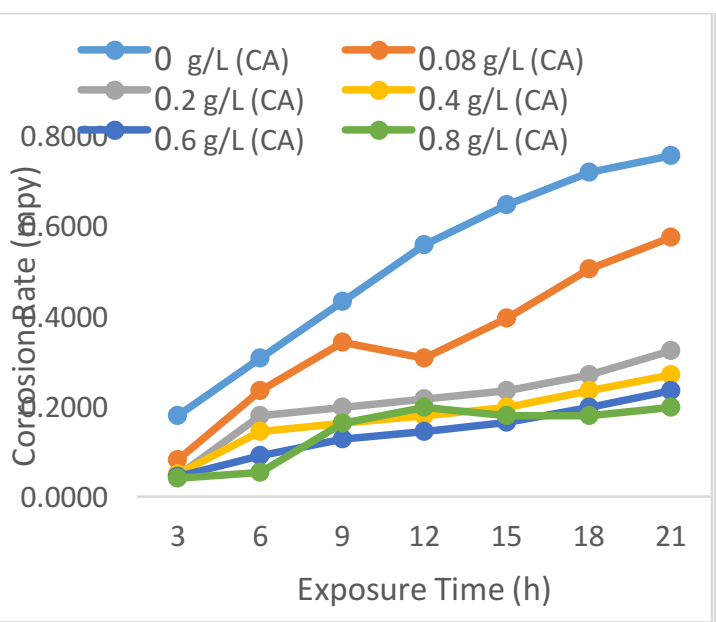

(b)
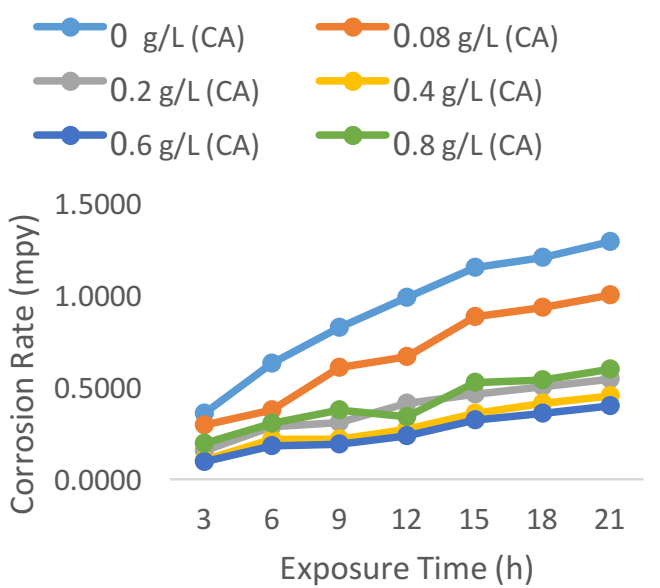

(c)

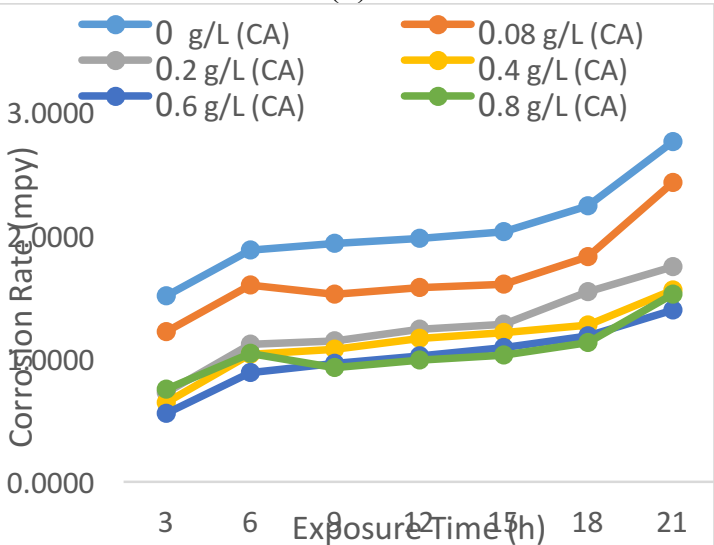

(d)

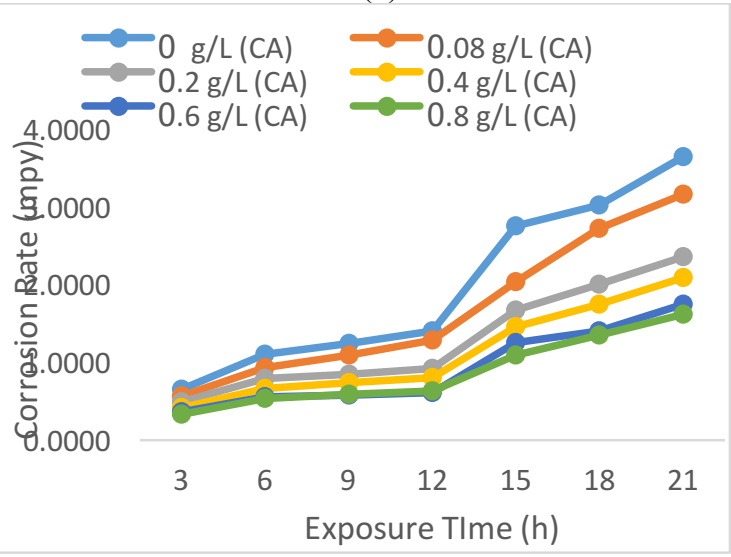

(e)

Fig. -4: The Effect of CA Extract Concentrations on Corrosion Rate of Low Carbon Steel (a) Room Temperature $298.16 \mathrm{~K}$ (b) $303 \mathrm{~K}$ (c) $313 \mathrm{~K}$ (d) 323 (e) $333 \mathrm{~K}$

\section{Electrochemical Extrapolation Studies Crateva adansonii (CA) Leaf Extract on Low Carbon Steel in Acidic Medium at $303-333 \mathrm{~K}$.}

Figure-5(a to d) are the Tafel Plots of potential (V) against the log of current (A) in an electrochemical corrosion system. Table -3 to -6 show electrochemical extrapolation of CA leaf extract on low carbon steel in acidic media at $303-333 \mathrm{~K}$. As shown in Fig.-5(a) and Table-3 at $303 \mathrm{~K}$. It was observed that the $E_{\text {corr }}$ values shift are more towards the less positive values as current potential, thereby having all the shift in $E_{\text {corr }}$ values to be less than $0.85 \mathrm{mV}$. This suggests that the extract exhibit a mixed type inhibitor. ${ }^{16,18}$ Notably, on the addition of CA leaf extract concentrations, the polarisation resistance $(\Omega)$ of the substrates in acidic media are found to be increased in all test solutions, Thereby increasing the inhibition efficiency. Invariably, CA leaf extract molecules has a higher degrees of coverage at 
noticeable concentrations. Also, deduced figures of corrosion current density and the corrosion rate decreased significantly with respect to blank and appreciably as the concentrations of the CA leaf extract increased as attested by other researchers. $16,21,24$

Figure-5(b) and Table-4, shows the results of the Tafel polarization curve from corrosion test solutions with varying concentrations of the CA leaf extract on substrates in acidic media at $313 \mathrm{~K}$. Moreover, the values of corrosion potential $\mathrm{E}_{\text {corr }}$ were closely identical for all concentrations of $\mathrm{CA}$ extract and equally having shift in the $\mathrm{E}_{\text {corr }}$ values to be less than $0.85 \mathrm{mV}$, which means that its act as Mixed type Inhibitor $^{20}$. Significantly, It is observed that as the level dosage of proposed ecofriendly inhibitor increases, the polarization resistance $(\Omega)$ of the system increases with an increasing inhibition efficiency, this suggest that the CA leaf extract has a greater affinity of coverage on the metallic surface according to other findings. ${ }^{21}$

Figure-5(c) and Table-5, shows that the electrochemical extrapolation for the substrates in acidic media with level dosage of CA leaf extract at a temperature of $323 \mathrm{~K}$. Vividly, the $\mathrm{E}_{\text {corr }}$ values for all concentrations are significantly close. It is found that the $\mathrm{E}_{\text {corr }}$ values are less than $0.85 \mathrm{mV}$ during all tested solutions on the substrates, this suggests CA leaf extract act as a mixed type inhibitor. Interestingly, the presence of CA leaf extract molecules enhances the polarisation resistance $(\Omega)$ of the system, which results in the slight increase in the inhibition efficiency at $323 \mathrm{~K}$, this implies that the CA leaf extract has the affinity to form a film-porous layer on the substrates. Also, values of corrosion current density decreased significantly with respect to blank. In clear view, the corrosion current density and corrosion rate of the system decreased with increasing concentrations of the proposed ecofriendly inhibitor. $^{22,28}$

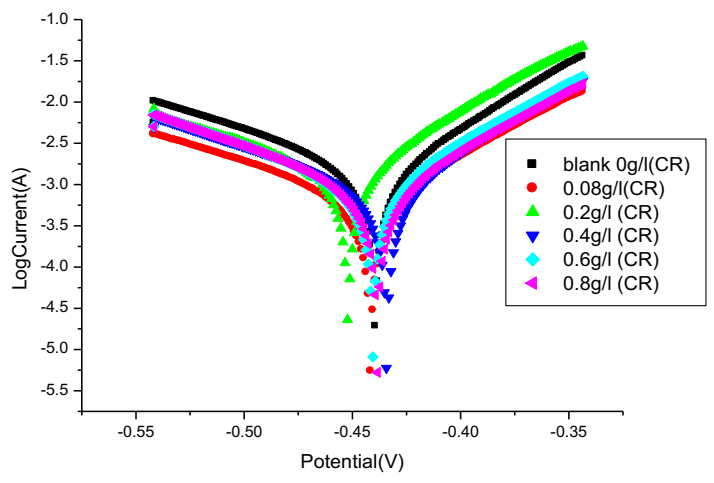

(a)

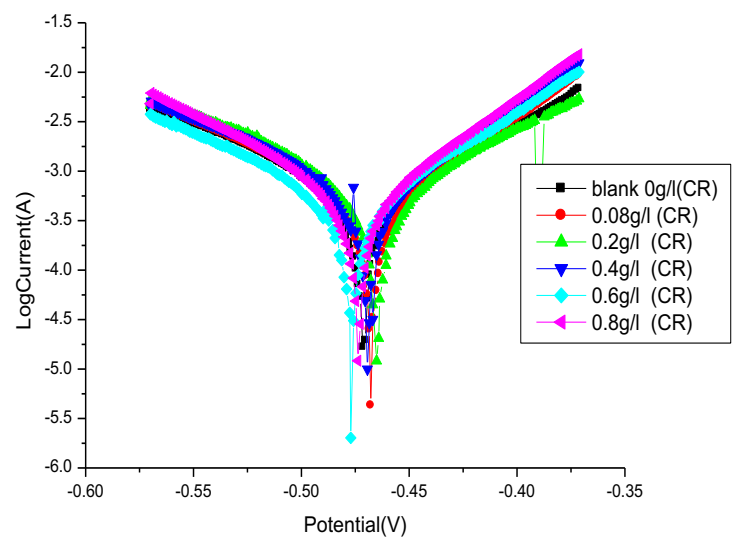

(c)

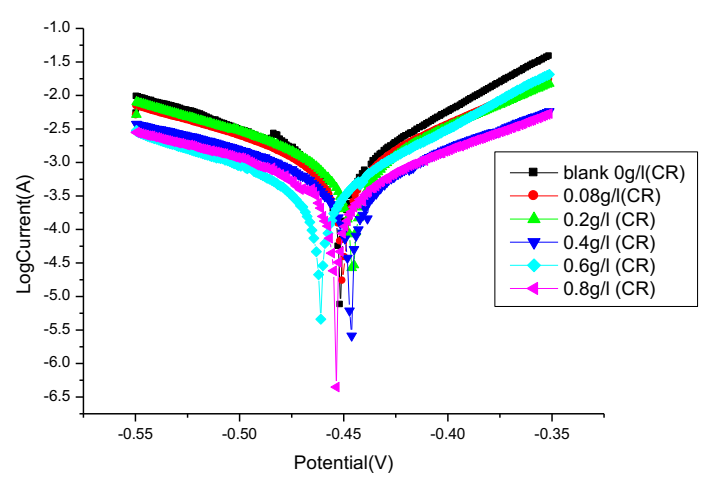

(b)

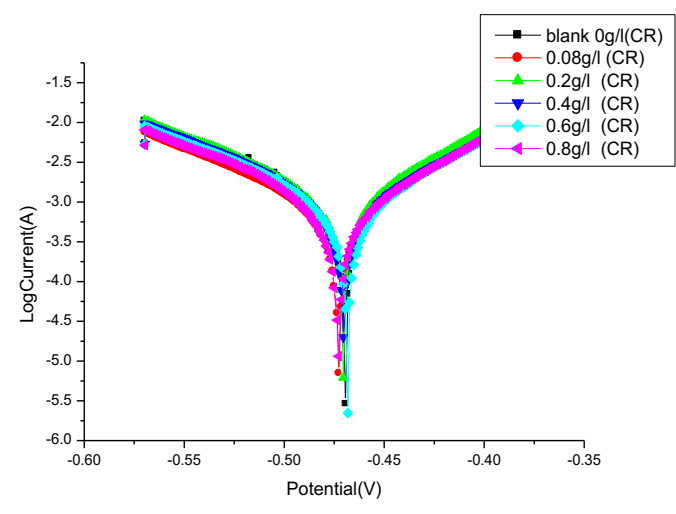

(d)

Fig.-5: The Tafel Plot for CA Leaf Extract at (a) $303 \mathrm{~K}$ and (b) $313 \mathrm{~K}$. (c) $323 \mathrm{~K}$ (d) $333 \mathrm{~K}$

Figure-5(d) and Table-6, shows the electrochemical extrapolation for substrates in acidic media with different concentrates of CA leaf extract at a temperature of $333 \mathrm{~K}$. The Tafel plot showed that the inhibitor at different level dosage exhibit an optimum inhibitive actions on the substrates compare to other temperatures. This suggests that the inhibitor molecules present in the CA extract blocks the 
surface of the substrate via the adsorption mechanism. Invariably, having a shift in the $\mathrm{E}_{\mathrm{corr}}$ values to be less than $0.85 \mathrm{mV}$, this suggests that the CA leaf extract act as a mixed type inhibitor. ${ }^{18,19}$ Upon addition of CA leaf extract concentrations, the polarisation resistance $(\Omega)$ of the system increases considerably as the inhibition efficiency also increases at 323 and $333 \mathrm{~K}$; this suggests the affinity of CA leaf coverage on the metal interface. It was observed that as the concentrations of the propose ecofriendly inhibitors increases, the corrosion rate and corrosion current density were further decreased with respect their exposure period. ${ }^{22}$

Table -3: Electrochemical Data's deducted From Tafel Plots for Low Carbon Steel immersed in Acidic Media in Addition of Crateva adansonii Extract Concentrations at $303 \mathrm{~K}$

\begin{tabular}{l|l|l|l|l|l}
\hline Parameter & $\begin{array}{l}\text { Ecorr } \\
(\mathrm{obs})(\mathrm{V})\end{array}$ & jcorr $\left(\mathrm{A} / \mathrm{cm}^{2}\right)$ & $\begin{array}{l}\text { Corrosion } \\
\text { Rate }\left(\mathrm{C}_{\mathrm{R}}\right)(\mathrm{mm} / \mathrm{yr})\end{array}$ & Polarization $(\Omega)$ & I.E (\%) \\
\hline BLANK & -0.45225 & $3.79 \mathrm{E}-05$ & 0.44130 & 24.57 & 0 \\
\hline 0.08 & -0.45673 & $2.56 \mathrm{E}-05$ & 0.29823 & 60.239 & 32.45 \\
\hline 0.2 & -0.45896 & $2.07 \mathrm{E}-05$ & 0.18600 & 31.356 & 45.38 \\
\hline 0.4 & -0.45863 & $1.60 \mathrm{E}-05$ & 0.18464 & 29.575 & 57.78 \\
\hline 0.6 & -0.46488 & $1.58 \mathrm{E}-05$ & 0.13253 & 28.113 & 58.31 \\
\hline 0.8 & -0.45675 & $1.14 \mathrm{E}-05$ & 0.02407 & 15.239 & 69.92 \\
\hline
\end{tabular}

Table -4: Electrochemical data's deducted From Tafel Plots for Low Carbon Steel immersed in Acidic Media in Addition of Crateva adansonii Extract Concentrations at $313 \mathrm{~K}$

\begin{tabular}{l|l|l|l|l|l}
\hline Parameter & $\begin{array}{l}\text { Ecorr } \\
(\mathrm{obs})(\mathrm{V})\end{array}$ & $\begin{array}{l}\text { jcorr } \\
\left(\mathrm{A} / \mathrm{cm}^{2}\right)\end{array}$ & $\begin{array}{l}\text { Corrosion Rate } \\
\left(\mathrm{C}_{\mathrm{R}}\right)(\mathrm{mm} / \mathrm{yr})\end{array}$ & Polarization $(\Omega)$ & I.E (\%) \\
\hline BLANK & -0.46850 & $6.12 \mathrm{E}-05$ & 0.71164 & 11.497 & 0 \\
\hline 0.08 & -0.48291 & $4.31 \mathrm{E}-06$ & 0.50175 & 27.542 & 29.58 \\
\hline 0.2 & -0.48096 & $3.38 \mathrm{E}-05$ & 0.39313 & 25.618 & 44.77 \\
\hline 0.4 & -0.47918 & $2.35 \mathrm{E}-05$ & 0.27380 & 22.640 & 61.60 \\
\hline 0.6 & -0.47018 & $1.75 \mathrm{E}-05$ & 0.20373 & 22.242 & 71.41 \\
\hline 0.8 & -0.46850 & $1.24 \mathrm{E}-05$ & 0.14408 & 16.031 & 79.74 \\
\hline
\end{tabular}

Table -5: Electrochemical data's deducted From Tafel Plots for Low Carbon Steel immersed in Acidic Media in Addition of Crateva adansonii Extract Concentrations at $323 \mathrm{~K}$

\begin{tabular}{l|l|l|l|l|l}
\hline Parameter & $\begin{array}{l}\text { Ecorr } \\
(\mathrm{obs})(\mathrm{V})\end{array}$ & $\begin{array}{l}\text { jcorr } \\
\left(\mathrm{A} / \mathrm{cm}^{2}\right)\end{array}$ & $\begin{array}{l}\text { Corrosion Rate } \\
\left(\mathrm{C}_{\mathrm{R}}\right)(\mathrm{mm} / \mathrm{yr})\end{array}$ & Polarization $(\Omega)$ & $\begin{array}{l}\text { I.E } \\
(\%)\end{array}$ \\
\hline BLANK & -0.46741 & $5.21 \mathrm{E}-05$ & 0.60560 & 18.639 & 0 \\
\hline 0.08 & -0.47850 & $3.38 \mathrm{E}-05$ & 0.39294 & 49.959 & 35.12 \\
\hline 0.2 & -0.47247 & $2.29 \mathrm{E}-05$ & 0.26697 & 48.094 & 56.05 \\
\hline 0.4 & -0.47156 & $2.05 \mathrm{E}-05$ & 0.23851 & 48.090 & 60.65 \\
\hline 0.6 & -0.46936 & $1.82 \mathrm{E}-05$ & 0.21196 & 46.426 & 65.07 \\
\hline 0.8 & -0.46741 & $1.28 \mathrm{E}-05$ & 0.14960 & 36.379 & 75.43 \\
\hline
\end{tabular}

\section{Adsorption Studies for Crateva adansonii Leaf Extract Using Lagmuir Adsorption Isotherm}

Figure -5, shows the adsorption studies for CA leaf extract using the best fitted isotherm (i.e. Langmuir adsorption isotherm) at temperature of $303-333 \mathrm{~K}$. A linear plot was obtained by plotting $\mathrm{C} / \theta$ against C.As shown from Fig.-5(a to d), a clear linear relationship of Langmuir isotherm with regression close to unity. This implies that Langmuir isotherm model is appropriate for the adsorption of CA extract leaf onto the metal surface in aggressive media and having a maximum regression coefficients of 0.9974 and minimum of 0.6641 for the adsorption of CA leaf extract in acidic media. ${ }^{11}$

\section{CONCLUSION}

Gravimetric and polarization studies investigated by the Potentials of Crateva adansonii ethanolic leaf extract on the corrosion of low carbon steel in acidic medium at room temperature and elevated temperature of (303-333 K). The following conclusions were made based on these studies: 
1. The corrosion rate decreases with increasing addition of CA extract, which suggests the adsorption of the extract molecules on the substrate.

2. The maximum inhibition efficiency was found to be $84.95 \%$ for CA extract in acidic medium.

3. The maximum inhibition efficiency was found to be $82.35 \%(\mathrm{CA})$ at $0.8 \mathrm{~g} / \mathrm{L}(303 \mathrm{~K})$ while optimum temperature of $333 \mathrm{~K}$ gives $60.13 \%(\mathrm{CA})$ at $0.8 \mathrm{~g} / \mathrm{L}$.

4. The Linear polarisation resistance studies and gravimetric results revealed that the inhibitive action of the extract molecules forming a protective layer of an oxide film on the substrate.

5. The adsorption of CA extract on mild steel from acidic medium obey Langmuir adsorption isotherms.

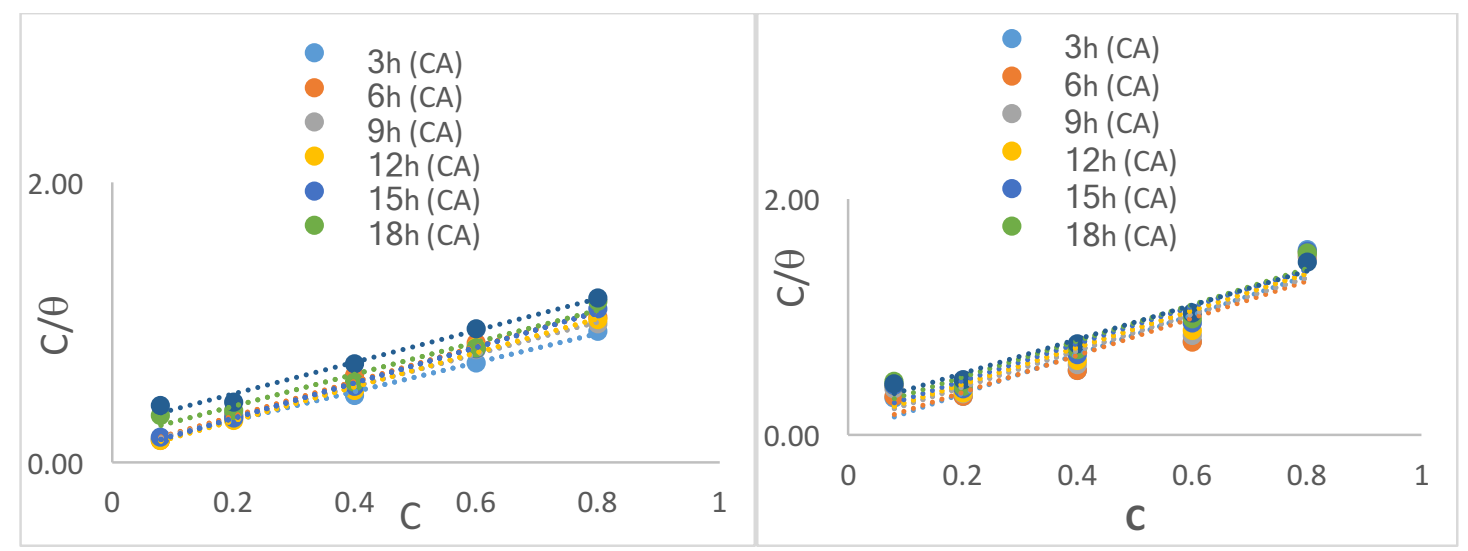

(a)

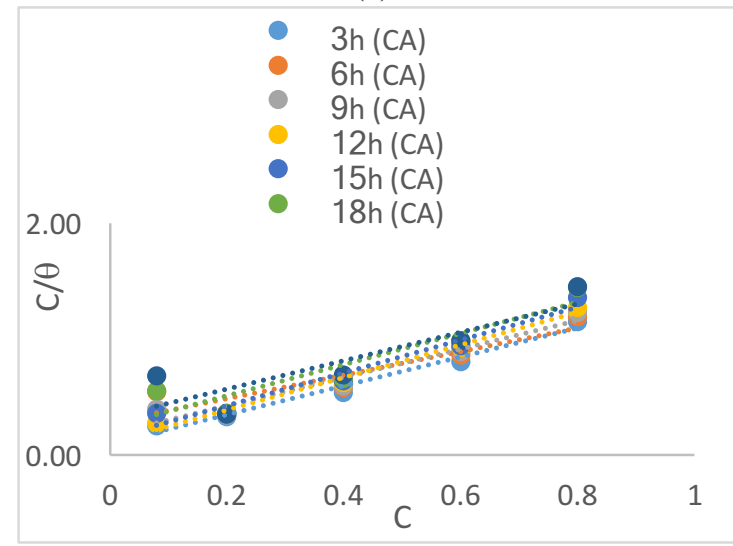

(c) (b)

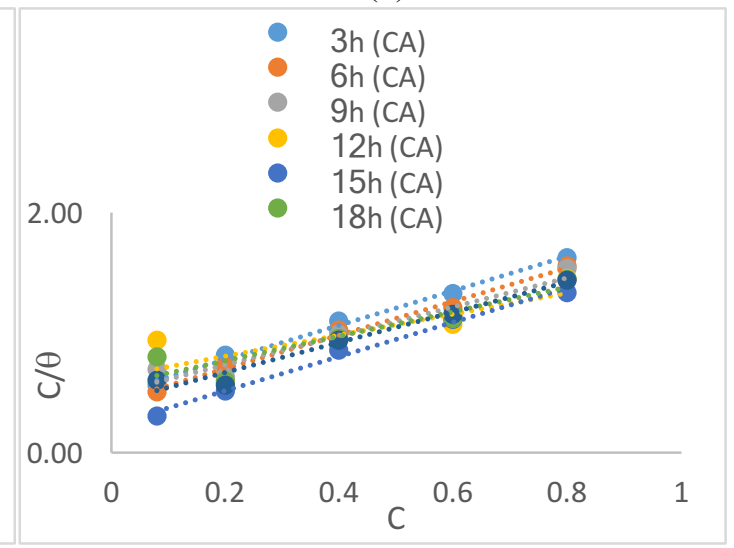

(d)

Fig.-5: Langmuir Adsorption Studies of Crateva adansonii Leaf Extract for An Immersion Time of (21h) at (a) $303 \mathrm{~K}$ (b) $313 \mathrm{~K}$ (c) 323 (d) $333 \mathrm{~K}$

Table -6: Electrochemical data's deducted From Tafel Plots for Low Carbon Steel immersed in Acidic Media in Addition of Crateva adansonii Extract Concentrations at $333 \mathrm{~K}$

\begin{tabular}{l|l|l|l|l|l}
\hline Parameter & $\begin{array}{l}\text { Ecorr } \\
(\mathrm{obs})(\mathrm{V})\end{array}$ & jcorr $\left(\mathrm{A} / \mathrm{cm}^{2}\right)$ & $\begin{array}{l}\text { Corrosion Rate } \\
(\mathrm{CR})(\mathrm{mm} / \mathrm{yr})\end{array}$ & Polarization $(\Omega)$ & I.E $(\%)$ \\
\hline BLANK & -0.43982 & $2.66 \mathrm{E}-05$ & 0.30944 & 20.589 & 0 \\
\hline 0.08 & -0.45587 & $1.47 \mathrm{E}-05$ & 0.22410 & 64.132 & 27.44 \\
\hline 0.2 & -0.44829 & $1.48 \mathrm{E}-05$ & 0.20962 & 38.353 & 32.33 \\
\hline 0.4 & -0.44906 & $1.58 \mathrm{E}-05$ & 0.18321 & 25.324 & 40.60 \\
\hline 0.6 & -0.44826 & $1.80 \mathrm{E}-05$ & 0.17229 & 21.611 & 44.36 \\
\hline 0.8 & -0.44146 & $1.93 \mathrm{E}-05$ & 0.17228 & 20.611 & 47.73 \\
\hline
\end{tabular}

\section{ACKNOWLEDGEMENT}

The authors would like to thank Covenant University Centre for Research Innovation and Discovery (CUCRID) Ota, Nigeria for financial provision towards the publication of this research work.

\section{REFERENCES}

1. R. Rosliza,Corrosion Resistance, (2012), DOI:10.5772/32952 
2. C. O. Ajanaku, J. O. Echeme, R. C. Mordi, T. F. Owoeye, O. S. Taiwo, O. Ejilude, and J. U Ataboh, Annual Research \& Review in Biology, 24(5), 1, (2018), DOI:10.9734/ARRB/2018/39314

3. O. Odeja, G. Obi, C. E. Ogwuche, E. E. Elemike, and Y. Oderinlo, Clinical Phytoscience, 1(1), 6, (2015), DOI:10.1186/s40816-016-0028-1

4. M. Scendo, Corrosion Science, 49(2), 373(2007), DOI:10.1016/j.corsci.2006.06.022

5. K. K. Alaneme, S. J. Olusegun and O. T Adelowo, Alexandria Engineering Journal, 55(1), 673(2016), DOI:10.1016/j.aej.2015.10.009

6. A. K. Satapathy, G. Gunasekaran, S.C Sahoo, K.Amit, and P.V. Rodrigues, Corrosion science, 51(12), 2848(2009), DOI:10.1016/j.corsci.2009.08.016

7. N. O. Eddy, International Journal of Physical Sciences, 4(4), 165(2009).

8. P. C. Okafor, V. I. Osabor, and E. E Ebenso, Pigment \& Resin Technology, 36(5), 299(2007), DOI: $10.1108 / 03699420710820414$

9. S. A. El-Rehim, M. A. Ibrahim, and K. F. Khaled, Journal of Applied Electrochemistry, 29(5), 593(1999), DOI:10.1023/A:1003450818083

10. B. Zerga, A. Attayibat, M. Sfaira, M. Taleb, B. Hammouti, M.E. Touhami, and Z. Rais, Journal of Applied Electrochemistry, 40(9), 1575(2010), DOI:10.1007/s10800-010-0164-0

11. K. R. Ansari, M. A. Quraishi, and A. Singh, Corrosion Science, 95, 62(2015), DOI: 10.1016/j.corsci.2015.02.010

12. U. M. Eduok, S. A. Umoren, and A. P. Udoh, Arabian Journal of Chemistry, 5(3), 325(2012), DOI: $10.1016 /$ j.arabjc.2010.09.006

13. E. E. Oguzie, Corrosion Science, 49(3), 1527(2007), DOI:10.1016/j.corsci.2006.08.009

14. E. A.Noor, and A. H. Al-Moubaraki., Materials Chemistry and Physics, 110(1), 145(2008), DOI:10.1016/j.matchemphys.2008.01.028

15. S. Perumal, S. Muthumanickam, A. Elangovan, R. Karthik, K.K. Mothilal, Journal of Bio- TriboCorrosion, 3(2),13(2017), DOI: 10.1007/s40735-017-0072-5

16. OSI. fayomi, I.G. Akande, O.O. Oluwole, D. Daramola, Chem Data Collect 17-18, 321(2018), DOI:10.1016/j.cdc.2018.10.006

17. H. Elgahawi, M. Gobara, A. Baraka W. Elthalabawy, Journal of Bio- Tribo-Corrosion, 3(4), 55,(2017), DOI: $10.1007 / \mathrm{s} 40735-017-0116-x$

18. W. Huilong, Z. Jiashen, and L. Jing, Anti-Corrosion Methods and Materials, 49(2), 127(2002), DOI: $10.1108 / 00035590210419371$

19. J. Haque, C. Verma, V. Srivastava, M.A. Quraishi E.E. Ebenso, Results Physics, 9,1481(2018), DOI: 10.1016/j.rinp.2018.04.069

20. OSI Fayomi, Silicon, 6(2),137(2014), DOI:10.1007/s12633-014-9177-3

21. A. Y. El-Etre, Applied Surface Science, 252(24), 8521(2006), DOI: 10.1016/j.apsusc.2005.11.066

22. A. O Okewale, and A.Olaitan, International Journal of Materials and Chemistry, 7(1), 5(2017), DOI: $10.5923 /$ j.ijmc. 20170701.02

23. A. K.Olusegun, N. C.Oforka, and E. E. Ebenso, The Journal of Corrosion Science and Engineering, 8(5), 1(2004), DOI:10.4028/www.scientific.net/AMR.701.323

24. S. A.Umoren, Z. M. Gasem, and I. B.Obot, Industrial \& Engineering Chemistry Research, 52(42), 14855(2013), DOI:10.5923/j.ijmc.20160601.03

25. S. A.Umoren, I. B. Obot, E. E. Ebenso, and N. O. Obi-Egbedi,. Desalination, 247(1-3), 561(2009), DOI: $10.9790 / 5736-0910012936$

26. A. K.Maayta, and N. A. F. Al-Rawashdeh, Corrosion Science, 46(5), 1129(2016), DOI: $10.1016 / \mathrm{S} 1006-706 \mathrm{X}(16) 30112-1$

27. S. Manimagalai, S., and P.Manjula, Journal of Material and Environmental Science, 6(6), 1629(2015), DOI: 10.1080/14620316.2016.1160544

28. R. T. Loto, C. A. Loto O. Joseph and G. Olanrewaju, Results in Physics, 6, 305(2016), DOI: $10.1016 /$ j.rinp.2016.05.013

29. I. Ukpong, O. Bamgboye and O. Soriyan, International Journal of Corrosion (2018), DOI:10.1155/2018/5648907

[RJC-5455/2019] 